658

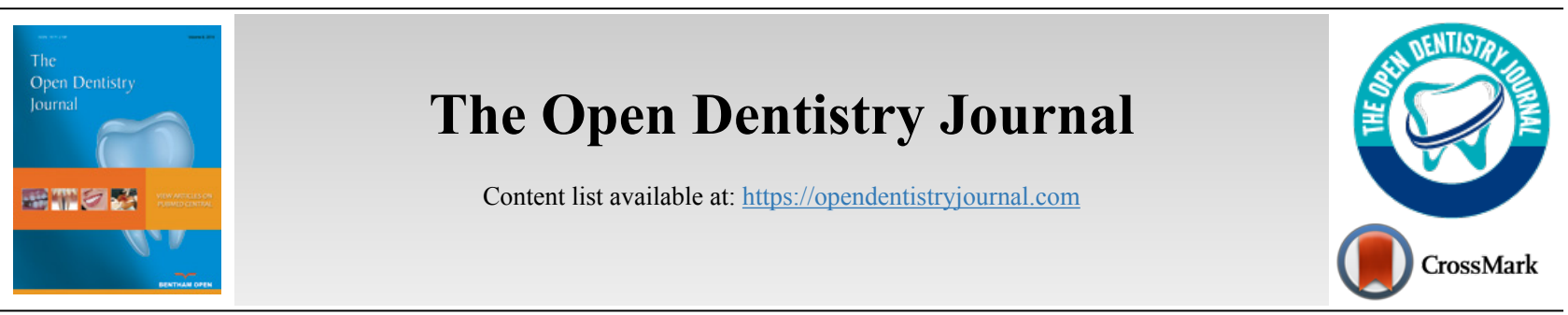

RESEARCH ARTICLE

\title{
Dimensional Stability of Elastomeric Impression Material After Disinfection Via Immersion and Microwave Irradiation
}

\author{
Noorhayati R. Mohd ${ }^{1, *}$, Ros A. Omar ${ }^{1, *}$ and Enas A. Etajuri ${ }^{1}$ \\ ${ }^{1}$ Department of Restorative Dentistry, Faculty of Dentistry, University of Malaya, 50603 Kuala Lumpur, Malaysia
}

\begin{abstract}
:
Aims:

This study aimed to evaluate and compare the dimensional stability of two elastomeric impression materials, namely polyvinyl siloxane (PVS) and vinyl siloxanether (VSE), subjected to chemical immersion and microwave irradiation for disinfection.

Materials and Methods:

Sixty discs of PVS and VSE impression materials each were prepared using a stainless-steel test die and ring in accordance with ANSI/ADA Specification No. 19. Twenty discs of each impression material were disinfected by chemical immersion for 10 min; another 20 discs were subjected to dry microwave irradiation for $3 \mathrm{~min}$. The other 20 discs served as a control group. Dimensional stability measurements were then performed using an image analyzer at $20 \times$ magnification. The data were analyzed by one-way analysis of variance $(\alpha=0.05)$ and Bonferroni (post hoc) test for multiple comparisons to detect significant differences between the groups.

Results:

When subjected to microwave irradiation, both PVS and VSE showed dimensional changes, but the changes were within the limit of $1.5 \%$ set by ANSI/ADA $(\mathrm{P}<0.00)$. VSE showed markedly better results than PVS for both disinfection methods. The immersion disinfection method resulted in a higher average percentage of linear dimensional changes than both the microwave irradiation and the control for VSE and PVS impression materials.

\section{Conclusion:}

VSE exhibited excellent dimensional stability than PVS under both chemical immersion and microwave irradiation. Microwave irradiation using conventional microwave ovens can be used in clinical settings as an alternative to other disinfection techniques because the dimensional changes of the elastomeric impression materials subjected to microwave irradiation have been observed to be within the clinically acceptable limit set by the ANSI/ADA standard.
\end{abstract}

Keywords: Elastomeric impression material, Dimensional stability, Chemical disinfectant, Microwave irradiation, Polyvinyl siloxane, Vinyl siloxanether.

Article History

Received: July 28, 2021

Revised: October 01, 2021

Accepted: November 11, 2021

\section{INTRODUCTION}

Impression making is a routine procedure in dental clinics [1]. Microbes present in patients' oral fluid may contaminate the impressions. To minimize the occurrence of contaminants, impressions should be rinsed under running tap water immediately after removal from a patient's mouth. Although rinsing with water significantly reduces the microbial count on the impression surface, it does not reduce the infection poten-

\footnotetext{
* Address correspondence to these authors at the Department of Restorative, Faculty of Dentistry, University of Malaya, 50603 Kuala Lumpur, Malaysia; E-mail: hayatiraja@um.edu.my
}

tial $[2,3]$.

Thus, the American Dental Association (ADA) recommends dental clinics and laboratories to follow appropriate disinfection protocols established by the Center for Disease Control (CDC) to prevent cross-infection between patients, dentists, and dental technicians [4, 5]. Several disinfection methods are used to disinfect different impression materials. The most common method is chemical disinfection, wherein the impression surface is treated chemically, either by immersion or spraying. Many chemical disinfection materials are commercially available in different compositions and 
concentrations, for e.g., glutaraldehyde, sodium hypochlorite $(\mathrm{NaOCl})$, hydrogen peroxide, iodophor, phenol, and chlorine compounds. Among these materials, glutaraldehyde is widely used as it has been reported to significantly disinfect microbes on the surface of irreversible hydrocolloid and elastomeric impression materials with minimum alteration of their physical properties [6].

In dentistry, microwave energy has been proposed as a simple alternative that addresses the drawbacks of chemical disinfection, and it is readily available, easy to use, and a lowcost technique. Studies related to the precision of elastomeric impression materials after microwave disinfection are scarce [7]. Microwave irradiation of elastomeric impression materials is a process that may help to achieve optimal disinfection, thereby avoiding cross-contamination between dental workers and laboratory staff [8]. Microwave irradiation reduces the microbial count more effectively than disinfection using $\mathrm{NaOCl}$ [9]. Another method is to use ultraviolet (UV) radiation, wherein the impression is placed in a UV unit chamber and irradiated by UV radiation from all directions to effectively disinfect microbes $[10,11]$. However, all forms of disinfections can cause undesirable changes in the dimensional accuracy and surface detail reproduction of impression because of the alteration in chemical or physical material properties [12].

Elastomeric impression materials undergo polymerization shrinkage owing to the rearrangement and crosslinking of polymer chain bonds. Polyvinyl siloxane (PVS) and polyether (PE) impression materials are among the most commonly used elastomeric materials in dental practice. These two materials undergo minor dimensional changes of $0.15 \%-0.20 \%$, respectively, mainly in the first hour after setting [13]. The main problems with PE impression materials are the formation of polymerization by-products and water absorption, which directly influence their dimensional stability. However, PVS impression materials do not experience these problems owing to the deficiency of polymerization by-products. A new elastomeric material, namely vinylsiloxanether (VSE) impression material, was introduced in 2009. This material is a mixture of vinyl dimethylpolysiloxane $(10 \%-50 \%)$, silicon dioxide $(30 \%-65 \%)$ and methyl hydrogen dimethylpolysiloxane $(3 \%-10 \%)$. Thus, it combines the properties of PVS and PE, resulting in improved resilience, hydrophilic properties, and flowability [14, 15].

Generally, no specific disinfection protocol exists for each type of impression material that reduces cross-contamination without adverse effects on the dimensional stability of the material. Several studies have evaluated the effectiveness of different disinfection methods on the dimensional stability of impression materials [16 - 19].

In a continuing effort to better understand the accuracy and dimensional stability of elastomeric impression materials, this study investigated the effect of disinfection using chemical immersion and microwave irradiation on the linear dimensional changes of PVS and VSE impression materials. The null hypothesis was that no significant difference would exist between the dimensional stabilities of PVS and VSE impression materials subjected to two different disinfection methods.

\section{MATERIALS AND METHODS}

Examix ${ }^{\circledR N D S}$ (GC America, IL, USA) and Identium ${ }^{\circledR}$ Medium (Kettenbach GmbH \& Co. KG, Eschenburg, Germany), which are impression materials made of PVS and VSE, respectively, were used in this study. Sixty impression discs were made from each material, of which 20 discs were randomly selected for immersion disinfection treatment, 20 for microwave irradiation disinfection, and the other 20 served as control. The impression discs were prepared according to ANSI/ADA specification no. 19 using a stainless-steel mold consisting of a test die and ring (Sabri Dental Enterprises, Inc., Downers Grove, IL). Two vertical lines d1 and d2 (25mm apart from each other) and three horizontal lines (A, B, C) were engraved on the metal die (Fig. 1a).

To mimic the oral temperature, the die was preheated in a $35{ }^{\circ} \mathrm{C}$ water bath (Zhengji HH-S4 Jiangsu, China) for $15 \mathrm{~min}$ prior to sample production.

Then, the impression material was injected into the stainless-steel mold (until the mold was filled completely), and the mold was covered with a polyethylene sheet. A glass slab was placed on top of the mold, and a constant pressure was applied on top of the slab using a $1 \mathrm{~kg}$ mass to standardize the material thickness during setting. This assembly was placed in the water bath for the setting time specified by the manufacturers. The discs were then carefully removed (Fig. 1b), and an alcohol swab was used to clean the die and ring before fabricating the next disc.

For disinfection, 20 discs of each elastomeric impression material were immersed in Silosept ${ }^{\circledR}$ (Kettenbach $\mathrm{GmbH}$ \& Co. KG, Eschenburg, Germany) for $10 \mathrm{~min}$ and then rinsed in running water for $15 \mathrm{~s}$. Silosept ${ }^{\circledR}$ is a granulated material based on active oxygen for immersion disinfection and contains pentakalium bis(peroxymonosulfate) bis(sulfate). Another 20 discs were subjected to dry microwave irradiation disinfection for 3 min using a conventional microwave oven (Sharp Microwave oven R212ZS 800W, 49X35X28, Osaka, Japan). The control samples were not subjected to disinfection.

To evaluate the dimensional stability, an image analyzer (Infinite Focus Real 3D Alicona, IL, USA) was used at 20× magnification to measure the distance of line $\mathrm{C}$ between lines $\mathrm{d} 1$ and $\mathrm{d} 2$ on the metal die $(\mathrm{L} 1=25 \mathrm{~mm})$ (Figs. 2 and 3); a similar measurement was carried out on the impression discs as well (L2). The measurements were performed in triplicate for each sample; all measurements were performed by the same examiner and under the same conditions. The percentage of dimensional changes was calculated as follows:

$$
\Delta \mathrm{L}=100 \times[(\mathrm{L} 1-\mathrm{L} 2) / \mathrm{L} 1],
$$

Where, $\mathrm{L} 1$ and $\mathrm{L} 2$ represent the distance between lines $\mathrm{d} 1$ and $\mathrm{d} 2$ on the test die and on the impression material, respectively (Fig. 3).

Data analysis was conducted using IBM ${ }^{\circledR} \quad$ SPSS $^{\circledR}$ StatisticsV22.0 (IBM Corp., NY, USA). Normality assumptions were tested using the Shapiro-Wilk test $(\alpha=0.05)$. A one-way analysis of variance (ANOVA) test was run to compare the mean dimensional changes. The significance value was set at $p=0.05$. The Bonferroni (post hoc) test for multiple 
comparisons was used to detect significant differences between the groups.

\section{RESULTS}

Descriptive statistics revealed normal distributions of the dependent variable $(\mathrm{a}=0.05)$. The mean dimensional changes and standard deviations (SD) of the VSE and PVS impression materials and disinfection methods are summarized in Table $\mathbf{1 .}$

Table 1. Descriptive statistics of the mean linear dimensional changes of VSE and PVS in all groups.

\begin{tabular}{|c|c|c|}
\hline \multicolumn{3}{|c|}{$\Delta \mathbf{L}$ values (\% Dimensional Change) (Mean \pm SD, $\mathbf{n}=\mathbf{2 0}$ Per } \\
Group)
\end{tabular}

One-way ANOVA showed a statistically significant difference $(p=0.000)$ between impression materials and the types of disinfection used. The mean of linear dimensional changes for VSE $(0.125 \%)$ was significantly less than that for PVS $(0.168 \%)$, as presented in Table 2 . A post hoc test was run for disinfection methods, and the results showed that the dimensional stability of the impression materials differed significantly $(\mathrm{P}<0.000)$ with every disinfection method. The mean value for the control group was $0.024 \%$, demonstrating better dimensional stability than the other disinfection groups. In contrast, microwave irradiation $(0.059 \%)$ produced better accuracy than immersion $(0.206 \%)$ with regard to impression materials, as shown in Table $\mathbf{3}$.

\section{DISCUSSION}

As discussed earlier, the null hypothesis was that no significant difference would exist in the dimensional stability of the PVS and VSE impression materials disinfected by chemical immersion and microwave irradiation in comparison to the control group. A statistically significant difference $(P<$ 0.00 ) between the groups was found; thus, the null hypothesis was rejected. Because VSE has a mixed composition of PVS and PE elastomeric impression materials, it would be significant to study its physical behavior under different test conditions. This study evaluated the dimensional stability of the PVS and VSE impression materials using a wellestablished method [4, 20 - 22]. As suggested by ANSI/ADA Specification No.19 for elastomeric impression materials [21], a stainless-steel mold was used to produce disc-shaped impression samples in order to measure the dimensional changes. This method allows for the identical reproduction of test conditions so that other researchers can make comparisons with other materials by utilizing the same study conditions. According to ANSI/ADA Specification No. 19, fine details of the $20 \mu \mathrm{m}$ line in the metal die must be reproduced in the elastomeric impression materials, and the linear dimensional changes should not exceed $1.5 \%$ [21, 22]. In the current study, the mean dimensional changes were less than $0.5 \%$ in all experimental groups, with the highest shrinkage of $0.220 \%$ and expansion of $-0.316 \%$.
The PVS and PE elastomeric impression materials generally demonstrated clinically accepted dimensional stability $[20,23]$. Because the VSE impression material is a hybrid form of PVS and PE elastomeric impression materials, it maintains similar mechanical and hydrophilic properties while achieving stability when set [24]. The study objective was to evaluate the linear dimensional changes of this material and compare it with PVS. However, the study findings indicated the statistically significant interactions between both materials to be within the clinically acceptable limit. The results showed VSE to be dimensionally more stable $(0.125 \%)$ than PVS (0.168\%). Similarly, Nassar et al. (2017) reported that VSE contracted when it was immersed in a disinfection solution and stored for two weeks in comparison to a nondisinfected VSE. $\left[{ }^{[} 19,20^{]}\right]$They reported an acceptable average of contraction of $0.200 \%-0.325 \%$. However, the test condition was different in the current study, and the dimensional changes were measured immediately after disinfection, without storing the material.

With regards to the effect of the disinfection method on the linear dimensional changes of PVS and VSE, the control group $(0.024 \%)$ exhibited significantly smaller dimensional changes than the microwave irradiation $(0.059 \%)$ and immersion $(0.206 \%)$ disinfection methods. The dimensional stability of VSE $(0.033 \%)$ was higher than that of PVS $(0.161 \%)$ when not subjected to disinfection, which was found to be similar to previous reports $[19,25]$.

In contrast, the linear dimensional changes of VSE $(0.192 \%)$ were significantly smaller than that of PVS $(0.220 \%)$ when subjected to chemical immersion disinfection. This result is similar to that of a previous study, wherein PVS (0.262\%) showed larger dimensional changes than VSE $(0.190 \%)$ after immersion in glutaraldehyde solution for $30 \mathrm{~min}$ [19]. This contraction could be attributed to the evaporation of volatile components in the impression material or to the continuous polymerization of the material in the first 24 hours $[13,26]$.

In contrast, under microwave irradiation, PVS expanded by- $0.32 \%$. This result is consistent with that of a previous study on the dimensional stability of five elastomeric impression materials with different consistencies after subjecting to chemical, microwave, and autoclave disinfection. A dimensional change of $-0.0024 \%$ to $-0.0028 \%$ for PVS has been reported when microwave irradiation was used [27]. The expansion of PVS could be ascribed to the chemical deterioration of the elastomeric material in dry conditions [28]. However, the expansion amount was very small and within the acceptable limit of $1.5 \%$ set by ANSI/ADA.

VSE exhibited the smallest dimensional change $(0.150 \%)$ among all disinfection groups; this could be because of the improved physical properties of VSE. The effects of microwave irradiation on the physical and mechanical properties of other types of dental material, such as denture base and denture reline materials, have been evaluated by various in vitro studies. These studies reported significant changes in material characteristics because of thermal effects, wherein the test material was immersed in distilled water when subjected to microwave irradiation [26 - 29]. However, in this study, the impression discs were subjected to dry microwave 
irradiation for $3 \mathrm{~min}$ because this duration resulted in a significant reduction in bacterial count on gypsum without adverse effects on its dimensional stability [30].
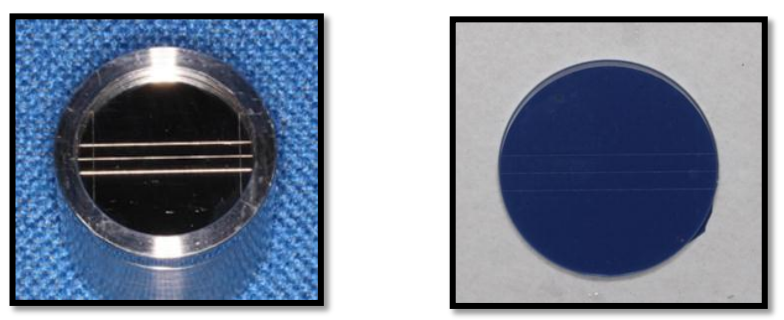

Fig. (1). (a) Stainless steel die, (b) impression material disc.

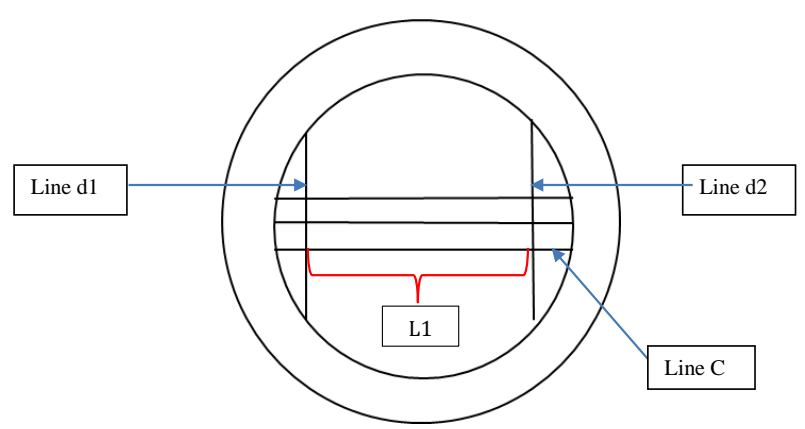

Fig. (2). Diagram of the stainless-steel ring and die line shows line C, measurement of $\mathrm{L} 1$ between $\mathrm{d} 1$ and $\mathrm{d} 2$.

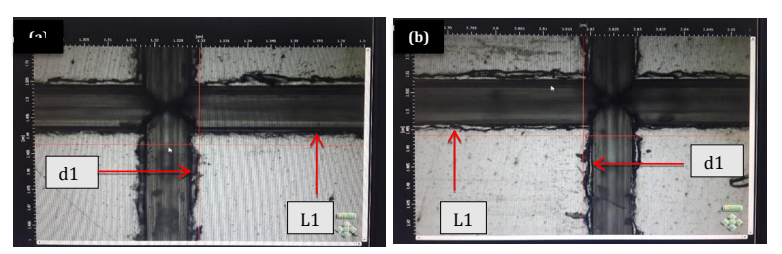

Fig. (3). Image analyzer view of the stainless-steel test die (a) L1 and $\mathrm{d} 1,(\mathbf{b}) \mathrm{L} 1$ and $\mathrm{d} 2$.

The microwave irradiation disinfection method significantly reduced the bacterial count of species, such as Streptococcus mutans, Staphylococcus aureus, Escherichia coli, and Pseudomonas aeruginosa. This method required a shorter processing time and had minimal effects on the physical properties of the impression materials when compared with those of the immersion technique [30 - 33].

Microwave irradiation yielded significantly superior results $(0.059 \%)$ than the immersion technique $(0.206 \%)$ for both PVS and VSE. This finding has been supported by another study, wherein the dimensional changes in elastomeric impression materials subjected to microwave irradiation were smaller compared with that of the immersion technique [34, 35]. Although the dimensional changes produced by immersion were greater for both materials, the results were still within the limit of $1.5 \%$ set by ANSI/ADA for linear dimensional changes. This finding agrees with that of the previous studies on elastomeric impression materials disinfected by chemical immersion, whose results were also found to be within the ADA specification [16, 36 - 38].

Therefore, microwave irradiation is beneficial to disinfect dental impressions without significantly deteriorating their physical properties. Thus, commercial microwave ovens can be used to disinfect elastomeric impressions as a practical, convenient, and fast alternative to other disinfection techniques.

The limitation of this study is that it focused only on the linear dimensional changes of VSE and PVS. Therefore, other physical properties of these materials, such as consistency, elastic recovery, compatibility with gypsum, and strain under compression, must also be studied. Additionally, the performance of VSE and PVS should be compared with that of other impression materials, such as polyether. Moreover, although studies have attempted to closely mimic oral conditions, impressions may act differently in clinical settings because of the presence of saliva. Therefore, our future study will involve an investigation of the performance of VSE and PVS in real clinical settings.

Table 2. Estimated marginal means of sample comparison of VSE and PVS impression material when subjected to disinfection. Pairwise comparison of materials, showing the mean difference between the $P$ value and $95 \%$ confidence interval $(p=0.05)$.

\begin{tabular}{|c|c|c|c|}
\hline $\begin{array}{c}\text { Impression } \\
\text { Material/Disinfection } \\
\text { Method }\end{array}$ & Mean & $\begin{array}{c}\text { Standard } \\
\text { Error }\end{array}$ & $\begin{array}{c}\text { 95\% Confidence } \\
\text { Interval }\end{array}$ \\
\hline VSE & 0.125 & 0.010 & $(0.104,0.145)$ \\
\hline PVS & 0.168 & 0.010 & $(0.047,0.089)$ \\
\hline
\end{tabular}

Table 3. Estimated marginal means of the sample comparison for all disinfection methods. Pairwise comparison of disinfection methods, showing the mean difference between the $P$ value and $95 \%$ confidence interval $(p=0.05)$.

\begin{tabular}{|c|c|c|c|}
\hline $\begin{array}{c}\text { Impression } \\
\text { Material/Disinfection } \\
\text { Method }\end{array}$ & Mean & $\begin{array}{c}\text { Standard } \\
\text { Error }\end{array}$ & $\begin{array}{c}\mathbf{9 5 \%} \text { Confidence } \\
\text { Interval }\end{array}$ \\
\hline Chemical immersion & 0.206 & 0.013 & $(0.181,0.231)$ \\
\hline Microwave irradiation & 0.059 & 0.013 & $(0.034,0.084)$ \\
\hline No treatment & 0.024 & 0.013 & $(-0.001,0.050)$ \\
\hline
\end{tabular}

\section{CONCLUSION}

VSE impression materials showed acceptable accuracy after disinfection by chemical immersion and microwave irradiation. Statistically significant differences between the two methods of disinfection were identified; however, the clinical influence of these differences was minor because the overall accuracy of the impression was within the $1.5 \%$ limit set by ANSI/ADA Specification No. 19. Therefore, a conventional microwave oven can potentially serve as a disinfection tool for VSE and PVS impression materials. 


\section{ETHICS APPROVAL AND CONSENT TO PARTI- CIPATE}

Not applicable.

\section{HUMAN AND ANIMAL RIGHTS}

Not applicable.

\section{CONSENT FOR PUBLICATION}

Not applicable.

\section{AVAILABILITY OF DATA AND MATERIALS}

The data supporting the findings of the article is available from corresponding author [N.R.M] upon reasonable request.

\section{FUNDING}

This research was financially supported by the University of Malaya Research Grant (Project No: RG514-13HTM).

\section{CONFLICT OF INTEREST}

The authors declare no conflict of interest, financial or otherwise.

\section{ACKNOWLEDGEMENTS}

The authors would like to thank Editage (www.editage.com) for English language editing.

\section{REFERENCES}

[1] Thota KK, Jasthi S, Ravuri R, Tella S. A comparative evaluation of the dimensional stability of three different elastomeric impression materials after autoclaving - an in vitro study. J Clin Diagn Res 2014; 8(10): ZC48-50

[http://dx.doi.org/10.7860/JCDR/2014/9768.5036] [PMID: 25478447]

[2] Sousa JC, Tabio AM, Silva A, Pereira T, Maia BS, Vasconcelos M. The effect of water and sodium hypochlorite disinfection on alginate impressions. Rev Port Estomatol Med Dent Cir Maxilofac 2013; 54: 8-12.

[3] Pal PK, Kamble SS, Chaurasia RR, Chaurasia VR, Tiwari S, Bansal D. Evaluation of different disinfectants on dimensional accuracy and surface quality of Type IV gypsum casts retrieved from elastomeric impression materials. J Int Oral Health 2014; 6(3): 77-81. [PMID: 25083038]

[4] American Dental Association. Council on Scientific Affairs and ADA Council on Dental Practice. Infection control recommendations for the dental office and the dental laboratory. J Am Dent Assoc 1996; 127(5): 672-80.

[http://dx.doi.org/10.14219/jada.archive.1996.0280] [PMID: 8642147]

[5] Kohn WG, Collins AS, Cleveland JL, Harte JA, Eklund KJ, Malvitz DM. Centers for Disease Control and Prevention (CDC). Guidelines for infection control in dental health-care settings. MMWR Recomm Rep 2003; 52(17): 1-61. [PMID: 14685139]

[6] Demajo JK, Cassar V, Farrugia C, et al. Effectiveness of disinfectants on antimicrobial and physical properties of dental impression materials. Int J Prosthodont 2016; 29(1): 63-7. [http://dx.doi.org/10.11607/ijp.4358] [PMID: 26757331]

[7] AlZain S. Effect of chemical, microwave irradiation, steam autoclave, ultraviolet light radiation, ozone and electrolyzed oxidizing water disinfection on properties of impression materials: A systematic review and meta-analysis study. Saudi Dent J 2020; 32(4): 161-70. [http://dx.doi.org/10.1016/j.sdentj.2019.12.003] [PMID: 32405219]

[8] Chidambaranathan AS, Balasubramanium M. Comprehensive review and comparison of the disinfection techniques currently available in the literature. J Prosthodont 2019; 28(2): e849-56. [http://dx.doi.org/10.1111/jopr.12597] [PMID: 28422353]

[9] Goel K, Gupta R, Solanki J, Nayak M. A comparative study between microwave irradiation and sodium hypochlorite chemical disinfection:
A prosthodontic view. J Clin Diagn Res 2014; 8(4): ZC42-6. [PMID: 24959515]

[10] Godbole SR, Dahane TM, Patidar NA, Nimonkar SV. "Evaluation of the effect of ultraviolet disinfection on dimensional stability of the polyvinyl silioxane impressions." an in-Vitro Study. J Clin Diagn Res 2014; 8(9): ZC73-6.

[PMID: 25386528]

[11] Nimonkar SV, Belkhode VM, Godbole SR, Nimonkar PV, Dahane T, Sathe S. Comparative evaluation of the effect of chemical disinfectants and ultraviolet disinfection on dimensional stability of the polyvinyl siloxane impressions. J Int Soc Prev Community Dent 2019; 9(2): $152-8$.

[http://dx.doi.org/10.4103/jispcd.JISPCD_406_18] [PMID: 31058065]

[12] Guiraldo RD, Borsato TT, Berger SB, Lopes MB, Gonini A Jr, Sinhoreti MA. Surface detail reproduction and dimensional accuracy of stone models: Influence of disinfectant solutions and alginate impression materials. Braz Dent J 2012; 23(4): 417-21.

[http://dx.doi.org/10.1590/S0103-64402012000400018] [PMID: 23207859]

[13] Sakaguchi RL, Powers JM. Craig's restorative dental materials. 13th ed. Philadelphia: Mosby Elsevier 2012; p. 293.

[14] Enkling N, Bürklein S, Jöhren P, Bayer S, Mericske-Stern R. A new vinylsiloxanether-material for impressions of implants and natural teeth: A prospective, clinical randomized trail. ZWR 2012; 118(06): 294-301.

[http://dx.doi.org/10.1055/s-0029-1233297]

[15] Enkling N, Bayer S, Jöhren P, Mericske-Stern R. Vinylsiloxanether: a new impression material. Clinical study of implant impressions with vinylsiloxanether versus polyether materials. Clin Implant Dent Relat Res 2012; 14(1): 144-51

[http://dx.doi.org/10.1111/j.1708-8208.2009.00240.x]

[PMID: 19793332]

[16] Soganci G, Cinar D, Caglar A, Yagiz A. 3D evaluation of the effect of disinfectants on dimensional accuracy and stability of two elastomeric impression materials. Dent Mater J 2018; 37(4): 675-84.

[http://dx.doi.org/10.4012/dmj.2017-097] [PMID: 29848853]

[17] Azevedo MJ, Correia I, Portela A, Sampaio-Maia B. A simple and effective method for addition silicone impression disinfection. J Adv Prosthodont 2019; 11(3): 155-61.

[http://dx.doi.org/10.4047/jap.2019.11.3.155] [PMID: 31297174]

[18] Millar B, Deb S. Effect of autoclave sterilisation on the dimensional stability and tear strength of three silicone impression materials. Open J Stomatol 2014; 4: 518-26.

[http://dx.doi.org/10.4236/ojst.2014.412069]

[19] Nassar U, Chow AK. Surface detail reproduction and effect of disinfectant and long-term storage on the dimensional stability of a novel vinyl polyether silicone impression material. J Prosthodont 2015; 24(6): 494-8.

[http://dx.doi.org/10.1111/jopr.12244] [PMID: 25522249]

[20] Nassar U, Flores-Mir C, Heo G, Torrealba Y. The effect of prolonged storage and disinfection on the dimensional stability of 5 vinyl polyether silicone impression materials. J Adv Prosthodont 2017; 9(3): 182-7.

[http://dx.doi.org/10.4047/jap.2017.9.3.182] [PMID: 28680549]

[21] Revised american dental association specification no. 19 for nonaqueous, elastomeric dental impression materials. J Am Dent Assoc 1977; 94(4): 733-41

[http://dx.doi.org/10.14219/jada.archive.1977.0334] [PMID: 265337]

[22] Naumovski B, Kapushevska B. Dimensional stability and acuracy of silicone - based impression materials using different impression techniques - A literature review. Prilozi (Makedon Akad Nauk Umet Odd Med Nauki) 2017; 38(2): 131-8.

[http://dx.doi.org/10.1515/prilozi-2017-0031] [PMID: 28991761]

[23] Nassar U, Tavoossi F, Pan YW, Milavong-Viravongsa N, Heo G, Nychka JA. Comparison of the contact angle of water on set elastomeric impression materials. J Can Dent Assoc 2018; 84: i6. [PMID: 31199723]

[24] Stober T, Johnson GH, Schmitter M. Accuracy of the newly formulated vinyl siloxanether elastomeric impression material. J Prosthet Dent 2010; 103(4): 228-39.

[http://dx.doi.org/10.1016/S0022-3913(10)60035-2] [PMID: 20362766]

[25] Rabeeba PK, Arundati NR, Henry J, et al. Comparative evaluation of surface detail reproduction and effect of disinfectant and long-term storage on dimensional stability of vinylpolyethersilicone with polyvinylsiloxane and polyether impression materials- In-Vitro study. Int J Adv Res (Indore) 2020; 8(02): 845-57. 
[http://dx.doi.org/10.21474/IJAR01/10517]

[26] Walker MP, Rondeau M, Petrie C, Tasca A, Williams K. Surface quality and long-term dimensional stability of current elastomeric impression materials after disinfection. J Prosthodont 2007; 16(5): 343-51.

[http://dx.doi.org/10.1111/j.1532-849X.2007.00206.x]

[PMID: 17559536]

[27] Ramakrishnaiah R, Kheraif AA, Qasim SS. The effect of chemical disinfection, autoclave, microwave sterilization on the dimensional accuracy of polyvinylsiloxane elastomeric impression materials. World Appl Sci J 2012; 17: 127-32.

[28] Al Kheraif AA. Surface roughness of polyvinyl siloxane impression materials following chemical disinfection, autoclave and microwave sterilization. J Contemp Dent Pract 2013; 14(3): 483-7.

[http://dx.doi.org/10.5005/jp-journals-10024-1349] [PMID: 24171994]

[29] Papaspyridakos P, Hirayama H, Chen CJ, Ho CH, Chronopoulos V, Weber HP. Full-arch implant fixed prostheses: A comparative study on the effect of connection type and impression technique on accuracy of fit. Clin Oral Implants Res 2016; 27(9): 1099-105. [http://dx.doi.org/10.1111/clr.12695] [PMID: 26374268]

[30] Banting DW, Hill SA. Microwave disinfection of dentures for the treatment of oral candidiasis. Spec Care Dentist 2001; 21(1): 4-8. [http://dx.doi.org/10.1111/j.1754-4505.2001.tb00216.x] [PMID: 11795452]

[31] Machado AL, Breeding LC, Vergani CE, da Cruz Perez LE. Hardness and surface roughness of reline and denture base acrylic resins after repeated disinfection procedures. J Prosthet Dent 2009; 102(2): 115-22.

[http://dx.doi.org/10.1016/S0022-3913(09)60120-7] [PMID: 19643225]

[32] Seo RS, Vergani CE, Pavarina AC, Compagnoni MA, Machado AL. Influence of microwave disinfection on the dimensional stability of intact and relined acrylic resin denture bases. J Prosthet Dent 2007;
98(3): 216-23.

[http://dx.doi.org/10.1016/S0022-3913(07)60058-4]

[PMID:

17854623

[33] Choi YR, Kim KN, Kim KM. The disinfection of impression materials by using microwave irradiation and hydrogen peroxide. J Prosthet Dent 2014; 112(4): 981-7.

[http://dx.doi.org/10.1016/j.prosdent.2013.12.017] [PMID: 24819529]

[34] Kamble SS, Khandeparker RV, Somasundaram P, Raghav S, Babaji RP, Varghese TJ. Comparative evaluation of dimensional accuracy of elastomeric impression materials when treated with autoclave, microwave, and chemical disinfection. J Int Oral Health 2015; 7(9): 22-4. [PMID: 26435611]

[35] Vatsal A, Prasadh S, Deepamala S, Abhishek P, Konthoujam S, Shruthi DP. Comparative evaluation of dimensional changes of elastomeric impression materials after disinfection with glutaraldehyde and microwave irradiation. J Int Oral Health

[36] Samra RK, Bhide SV. Comparative evaluation of dimensional stability of impression materials from developing countries and developed countries after disinfection with different immersion disinfectant systems and ultraviolet chamber. Saudi Dent J 2018; 30(2): 125-41. [http://dx.doi.org/10.1016/j.sdentj.2017.11.005] [PMID: 29628736]

[37] Martins F, Branco P, Reis J, Barbero Navarro I, Maurício P. Dimensional stability of two impression materials after a 6-month storage period. Acta Biomater Odontol Scand 2017; 3(1): 84-91.

[http://dx.doi.org/10.1080/23337931.2017.1401933]

[PMID: 29242816]

[38] Vrbova R, Bradna P, Bartos M, Roubickova A. The effect of disinfectants on the accuracy, quality and surface structure of impression materials and gypsum casts: A comparative study using light microscopy, scanning electron microscopy and micro computed tomography. Dent Mater J 2020; 39(3): 500-8. [http://dx.doi.org/10.4012/dmj.2019-065] [PMID: 31827058]

\section{2021 R. Mohd et al.}

This is an open access article distributed under the terms of the Creative Commons Attribution 4.0 International Public License (CC-BY 4.0), a copy of which is available at: https://creativecommons.org/licenses/by/4.0/legalcode. This license permits unrestricted use, distribution, and reproduction in any medium, provided the original author and source are credited. 